\title{
Short-Term Efficacy and Safety of Omidenepag Isopropyl in Patients with Normal-Tension Glaucoma
}

This article was published in the following Dove Press journal: Clinical Ophthalmology

\author{
Kenji Inoue' \\ Junji Inoue ${ }^{2}$ \\ Shiho Kunimatsu-Sanuki ${ }^{2}$ \\ Norie Nozaki ${ }^{3}$ \\ Kosuke Shimizu ${ }^{4}$ \\ Kyoko Ishida (iD) \\ Goji Tomita ${ }^{1,5}$ \\ 'Inouye Eye Hospital, Chiyoda-Ku, Tokyo, \\ Japan; ${ }^{2}$ Nishikasai Inouye Eye Hospital, \\ Edogawa-Ku, Tokyo, Japan; ${ }^{3}$ Omiya \\ Inouye Eye Clinic, Saitama-Shi, Saitama, \\ Japan; ${ }^{4}$ Sapporo Inouye Eye Clinic, \\ Sapporo-Shi, Sapporo, Japan; \\ ${ }^{5}$ Department of Ophthalmology, Toho \\ University Ohashi Medical Center, \\ Meguro-ku, Tokyo, Japan
}

Correspondence: Kenji Inoue Inouye Eye Hospital, Chiyoda-Ku, Tokyo, Japan

Tel +8I 0332950911

Fax +810332950917

Email 2inoue-k@inouye-eye.or.jp
Purpose: To retrospectively evaluate the short-term efficacy of omidenepag isopropyl (EYBELIS $0.002 \%$ ) by assessing its intraocular pressure (IOP)-lowering capability and safety in patients with normal-tension glaucoma (NTG).

Patients and Methods: Fifty-four NTG patients (54 eyes) who were newly administrated with omidenepag isopropyl were enrolled in the study. The subjects comprised 22 men and 32 women, and the mean age of the subjects was $55.0 \pm 14.1$ years. The mean deviation value using the Humphrey visual field test program (30-2 SITA Standard) was $-5.03 \pm 3.38 \mathrm{~dB}$. The following data were retrieved from the medical records and used for retrospective analyses: IOP at baseline 1-2 months and 3-4 months after administration. The frequency of non-responder patients who had less than $10 \%$ IOP reduction was evaluated. Patients were observed for adverse reactions and dropouts at each time point.

Results: IOP at baseline, after 1-2 months and after 3-4 months was $15.7 \pm 2.6 \mathrm{mmHg}, 13.5$ $\pm 2.3 \mathrm{mmHg}$, and $13.6 \pm 2.4 \mathrm{mmHg}$, respectively. There was a significant decrease in IOP after administration $(\mathrm{p}<0.0001)$. Eleven patients $(22.4 \%)$ were non-responders. Adverse reactions occurred in 4 patients $(7.4 \%)$, including conjunctival hyperemia in 3 patients (after 1 week, 2 weeks, and 1 month, respectively) and eye pain in 1 patient (after 1 month). Five patients (9.3\%) dropped out of the study because of an adverse reaction in 3 patients, insufficient IOP reduction in 1 patient, and discontinuation of follow-up of 1 patient at our institution.

Conclusion: After administration of omidenepag isopropyl, IOP in patients with NTG was significantly decreased. However, adverse reactions occurred in $7.4 \%$ of patients.

Keywords: intraocular pressure, adverse reactions, EP2 receptor agonist, conjunctival hyperemia

\section{Introduction}

The purpose of treating glaucoma is to stop or slow down the progression of visual field defects. To date, the lowering of intraocular pressure (IOP) is the only treatment with evidence. ${ }^{1,2}$ The treatment for lowering the IOP is administered through eye drops, oral medicines, lasers, or surgery. Initially, a single-agent eye drop is administered. ${ }^{3}$ Prostaglandin analog eye drops have strong efficacy for lowering IOP. Additionally, a few systemic adverse reactions have been reported; and, owing to the once-daily administration, these eye drops are convenient to use, thereby making them the first-choice medication for lowering IOP. ${ }^{3}$ However, peculiar local adverse reactions including eyelid pigmentation, iris pigmentation, 
eyelash bristle, and the deepening of the upper eyelid sulcus have been frequently reported with the use of prostaglandin analogs. ${ }^{4,5}$ A previous study has suggested the prevalence of non-responders for prostaglandin analogs. ${ }^{6}$ Therefore, the development of new medication with a high IOP-lowering effect, a little systemic or local adverse reactions, and once-daily administration is needed. Omidenepag isopropyl is an agonist to the EP2 receptor and has an IOP lowering activity that is mediated by a mechanism different from the existing prostaglandin analog eye drops, and it has been approved for the treatment of glaucoma in Japan since November 2018. The clinical trials have shown sufficient IOP lowering effects and high safety of omidenepag isopropyl eye drops in patients with primary open-angle glaucoma (POAG) and ocular hypertension. ${ }^{7,8}$ In addition, a previous study has reported that many patients who had developed prostaglandin-associated periorbitopathy (PAP), showed improvement after administration of omidenepag isopropyl. ${ }^{9}$ Omidenepag isopropyl acts by a mechanism different from the previous medications, and to the best of our knowledge, no study has evaluated the effect and safety of omidenepag isopropyl in patients with normal-tension glaucoma (NTG), which is the most common type of glaucoma diagnosed in the Japanese. ${ }^{10}$ Therefore, in the present study, we retrospectively investigated the short-term IOP lowering effects and safety of omidenepag isopropyl in patients with NTG.

\section{Patients and Methods}

Fifty-four patients (54 eyes) with NTG were administered with omidenepag isopropyl (EYBELIS ophthalmic solution $0.002 \%$, Santen Pharmaceutical Co., Ltd., Japan) at Inouye Eye Hospital Group (Inouye Eye Hospital, Ochanomizu Inouye Eye Clinic, Nishikasai Inouye Eye Hospital, Omiya Inouye Eye Clinic, and Sapporo Inouye Eye Clinic) for 17 months from December 2018 to April 2020. The diagnostic criteria used for NTG were as follows: (1) typical morphologic characteristics, such as thinning of the optic disc rim and defects in the retinal nerve fiber layer; (2) an abnormal visual field detected with high reliability and reproducibility, and corresponding to the criteria outlined in (1); (3) exclusion of other eye diseases or congenital abnormalities that could cause an abnormal visual field; (4) a primary open-angle on gonioscopy; and (5) IOP $\leq 21 \mathrm{mmHg}$ on serial measurements, allowing for diurnal variation. The patients in whom both the eyes satisfied the inclusion criteria, the eye with the higher
IOP at baseline was enrolled; and if the IOP was the same in both the eyes, the right eye was enrolled. The following patients were excluded from the study: (1) those with aphakic eye or intraocular lens, ie, in whom cataract surgery had been performed. These patients have a risk of macular edema, including cystoid macular edema, and vision impairment or vision loss due to macular edema, and (2) those who had a plan of undergoing cataract surgery within 6 months of enrolment in the study.

Patients were administered with omidenepag isopropyl once daily in the morning. The following data were retrieved from the medical records and used for retrospective analyses: IOP (measured at least twice in each patient) at baseline prior to treatment administration, at 1-2 months after administration, and 3-4 months after administration. IOP was measured with a Goldmann tonometer. The IOP value at the day administered omidenepag isopropyl was measured as the baseline IOP. Of the 54 patients, 52 had never used any medication for glaucoma. Of the remaining two patients, one used latanoprost until 3 months before enrolment in the present study and the other used latanoprost/carteolol fixed combination until 1 month before enrolment in the present study. Eight physicians were responsible for IOP measurement as this was a collaborative research study. The attending physician consistently took charge of IOP measurement in the same patient. The data for IOP before and after administration (at 1-2 months and 3-4 months) were compared. The reduction in IOP was calculated from baseline to 1-2 months and 3-4 months after administration of omidenepag isopropyl. Patients were categorized according to whether their IOP was reduced by $<10 \%, \geq 10 \%$ but $<20 \%$, and $\geq 20 \%$ at $1-2$ months and 3-4 months after administration of omidenepag isopropyl. The frequency of non-responders was also evaluated. Based on a previous report, the patients in whom the IOP reduction was less than $10 \%$ at both $1-2$ months and 3-4 months after administration were defined as non-responders. ${ }^{6}$ Adverse reactions and dropouts from this study were also investigated. At each patient follow-up visit, the physicians emphasized the importance of medication adherence. The occurrence of adverse reactions was determined from measurement results and patient interviews at each visit.

The study protocol was approved by the Inouye Eye Hospital ethics committee (approval number: 201812-2) and was conducted in accordance with the tenets of the Declaration of Helsinki. The study information was notified in the hospital, and the subjects had the opportunity 
for refusal of inclusion in the study. All patients gave informed consent prior to enrolment in the study.

\section{Statistical Analyses}

IOP changes were analyzed by analysis of variance and Bonferroni correction. Comparisons of the IOP reduction and percentage IOP reduction were analyzed by the Wilcoxon signed-rank test. All statistical analyses were conducted using IBM SPSS-Statistics 22 (IBM Corp., Armonk, NY, USA). Differences with p-value $<0.05$ were considered statistically significant.

\section{Results}

\section{Subjects}

The subjects in our study comprised 22 men and 32 women. The mean age was $55.0 \pm 14.1$ years (mean \pm standard deviation; range, $22-78$ years). The mean IOP at baseline was $15.7 \pm 2.6 \mathrm{mmHg}$ (range, $10-21 \mathrm{mmHg}$ ). The mean deviation value measured by the Humphrey visual field test program (30-2 SITA Standard) was $-5.03 \pm 3.38 \mathrm{~dB}$ (range, -14.41 to $-0.26 \mathrm{~dB}$ ). We considered that medication adherence was satisfactory because there was no mention of poor adherence in the medical records of enrolled patients.

\section{Intraocular Pressure}

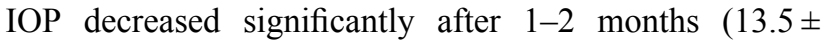
$2.3 \mathrm{mmHg})$ and $3-4$ months $(13.6 \pm 2.4 \mathrm{mmHg})$ of omidenepag isopropyl administration as compared to IOP at the baseline $(15.7 \pm 2.6 \mathrm{mmHg})(\mathrm{P}<0.0001)$ (Figure 1). The mean difference in IOP reduction was $2.1 \pm 1.8 \mathrm{mmHg}$ after 1-2 months and $2.0 \pm 2.0 \mathrm{mmHg}$ after $3-4$ months,

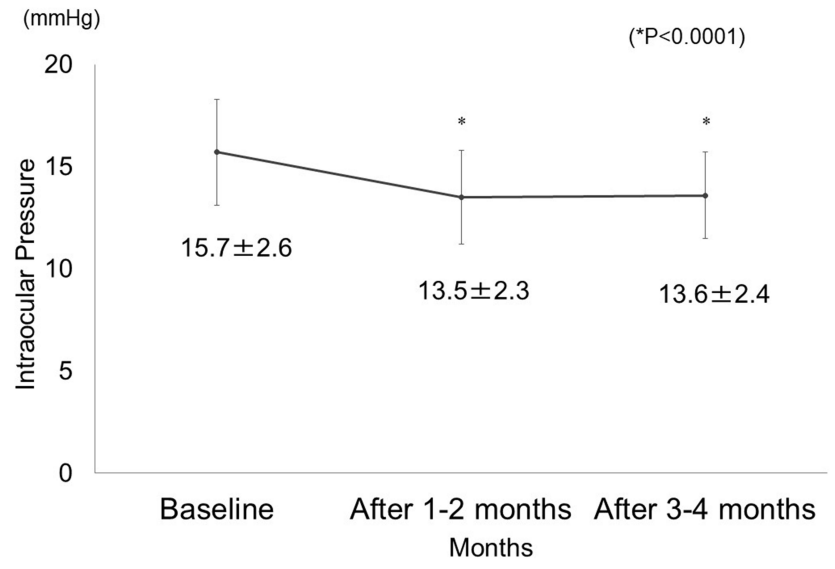

Figure I Intraocular pressure before and after the administration of omidenepag isopropyl $(* \mathrm{P}<0.000 \mathrm{I})$. but it was not statistically significant $(\mathrm{P}=0.5227)$. The IOP reduction was $12.8 \pm 10.6 \%$ after $1-2$ months and $12.0 \pm$ $12.8 \%$ after $3-4$ months, but the difference was not statistically significant $(\mathrm{P}=0.3368)$. IOP reduction at $1-2$ months compared with IOP at baseline was $<10 \%$ in 17 patients $(33.3 \%), \geq 10 \%$ but $<20 \%$ in 24 patients $(47.1 \%)$, and $\geq 20 \%$ in 10 patients $(19.6 \%)$. At $3-4$ months, IOP reduction compared to IOP at baseline was $<10 \%$ in 16 patients $(32.7 \%), \geq 10 \%$ but $<20 \%$ in 20 patients $(40.8 \%)$, and $\geq 20 \%$ in 13 patients (26.5\%) (Figure 2). There were 11 non-responder patients (22.4\%).

\section{Safety}

Four patients (7.4\%) showed adverse reactions as follows: conjunctival hyperemia in 3 patients (5.6\%) after 1 week, 2 weeks, and 1 month, respectively; and eye pain in 1 patient $(1.9 \%)$ after 1 month (Table 1$)$. Loss of visual acuity by 2 or more stages was observed in 1 patient $(1.9 \%)$. Progression of the cataract was the underlying cause for loss of visual acuity in this patient; there was no cystoid macular edema as evident by optical coherence tomography. Five patients $(9.3 \%)$ were discontinued the administration of omidenepag isopropyl because of the following reasons: conjunctival hyperemia in 2 patients $(3.7 \%)$ at 1 week and 2 weeks after the administration, eye pain in 1 patient $(1.9 \%)$ at 1 month after administration, insufficient IOP lowering effect in 1 patient $(1.9 \%)$ at 2 months after administration, and discontinuation of follow-up of 1 patient (1.9\%) at our institution because of switching to another doctor at a different institution 1 month after administration (Table 1).

\section{Discussion}

Omidenepag isopropyl is an agonist selective to the EP2 receptor, which is a type of prostanoid receptor. It works on two parts, the uveoscleral outflow and the trabecular outflow, thereby facilitating the outflow of the aqueous humor. ${ }^{11,12}$ The EP2 receptor is present in the ciliary body, trabecula, iris, cornea, conjunctiva, and the retina. It has been reported that the smooth muscles relax due to the receptor and the IOP decreases due to the effect on the extracellular matrix. ${ }^{13}$ Because omidenepag isopropyl has been approved for the treatment of glaucoma in Japan since November 2018, the efficacy and safety of omidenepag isopropyl, which is known to act by a novel mechanism, were investigated in this study.

In the present study, IOP decreased significantly both at 1-2 months and 3-4 months after administration. The 

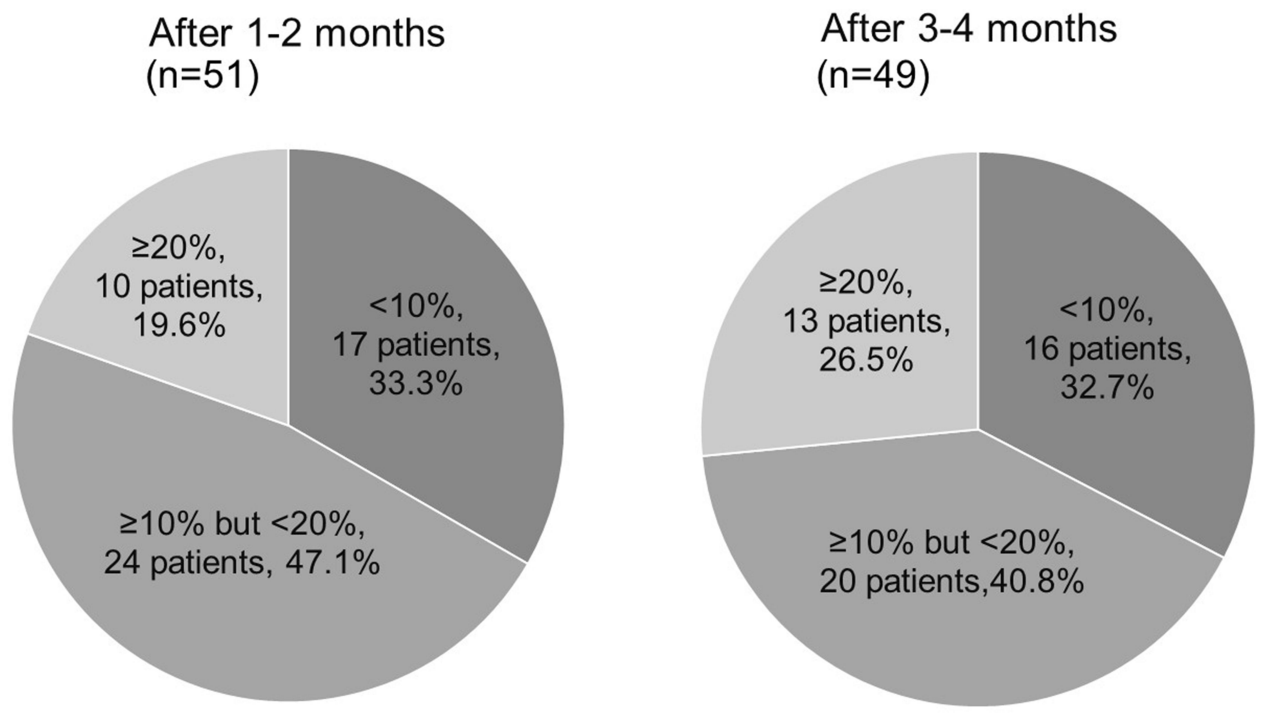

N.S. $(P=0.6884)$

Figure 2 Percentage reduction in intraocular pressure after the administration of omidenepag isopropyl.

Abbreviation: N.S., not significant.

mean differences in IOP reduction after 1-2 months and 3-4 months were $12.8 \% \pm 10.6 \%$ and $12.0 \% \pm 12.8 \%$, respectively. In a clinical trial conducted in the United States, omidenepag isopropyl was administered to the subjects for four weeks and the diurnal variation of IOP was investigated. ${ }^{7}$ The mean percentage difference in IOP reduction was $27.5 \%$ to $32.0 \%$. In similar clinical trials conducted in Japan, the mean difference in IOP reduction has been reported to be $21.4 \%$ to $21.8 \%{ }^{7}$ In another clinical trial conducted in Japan, the mean percentage difference in IOP reduction after 4 weeks of omidenepag isopropyl administration was $24.9 \%{ }^{8}$ The lowering of IOP in those clinical trials was greater than the results of the present study. The subjects of the clinical trials were patients with POAG or ocular hypertension, and IOP at the baseline in the clinical trials $(24.8 \pm 1.7 \mathrm{mmHg}$ in the United States, $23.8 \pm 1.4 \mathrm{mmHg}$ and $23.78 \pm 1.73 \mathrm{mmHg}$ in Japan) was higher than the IOP at baseline in the present study $(15.7 \pm 2.6 \mathrm{mmHg}$ ), and this may have influenced the results. ${ }^{7,8}$ Thus, omidenepag isopropyl may have weaker IOP-lowering effects in NTG than in POAG or ocular hypertension.

A study has been reported, wherein, the IOP lowering effects of prostaglandin analogs for Japanese patients with glaucoma were evaluated by network meta-analysis. ${ }^{14}$ Among the prostaglandin analog eye drops (bimatoprost, latanoprost, travoprost, and tafluprost), bimatoprost showed significantly strong IOP-lowering effects

Table I Adverse Reactions and Dropouts After Administration of Omidenepag Isopropyl

\begin{tabular}{|l|l|l|l|}
\hline Adverse Reactions (4 Patients, 7.4\%) & Number of Patients & Time Point & Progress \\
\hline Conjunctival hyperemia & $3(5.6 \%)$ & $\begin{array}{l}\text { I week } \\
2 \text { weeks } \\
\text { I month } \\
\text { I month }\end{array}$ & $\begin{array}{l}\text { Discontinued administration } \\
\text { Discontinued administration } \\
\text { Continued administration } \\
\text { Discontinued administration }\end{array}$ \\
\hline Dye pain & I (I.9\%) & Time Point & Details \\
\hline Adverse reactions & Number of Patients & $\begin{array}{l}\text { I week } \\
2 \text { weeks } \\
\text { I month } \\
2 \text { months } \\
\text { I month }\end{array}$ & $\begin{array}{l}\text { Conjunctival hyperemia } \\
\text { Conjunctival hyperemia } \\
\text { Eye pain }\end{array}$ \\
\hline
\end{tabular}

Abbreviation: IOP, intraocular pressure. 
compared to latanoprost. Further, IOP lowering effects of prostaglandin analogs for NTG patients after 3-months or 12-months of administration have been reported (Table 2). ${ }^{15-20}$ Similar values of IOP reduction $(12.0 \pm$ $12.8 \%$ ) were observed in the present study. Omidenepag isopropyl has been considered to have strong IOP lowering effects similar to prostaglandin analog eye drops in NTG patients.

In the present study, the number of patients who had less than 10\% IOP reduction was 17 (33.3\%) after 1-2 months and $16(32.7 \%)$ after 3-4 months. Eleven patients $(22.4 \%)$ had less than $10 \%$ IOP reduction at both 1-2 months and 3-4 months after administration. In our previous report considering the IOP fluctuation, the patients who had less than $10 \%$ IOP reduction at both 1 month and 3 months after administration were defined as non-responder cases. ${ }^{6}$ The frequency of non-responders among patients with NTG was $15.0 \%, 14.1 \%, 7.7 \%$, and $0 \%$ for latanoprost, travoprost, tafluprost, and bimatoprost, respectively. ${ }^{6}$ The frequency of non-responder patients for omidenepag isopropyl in the present study was $22.4 \%$, which is higher than that reported in the previous study. ${ }^{6}$ The IOP at baseline in this study $(15.7 \pm 2.6 \mathrm{mmHg})$ was lower than the IOP for other medications (16.4 \pm $2.3 \mathrm{mmHg}, 16.5 \pm 2.5 \mathrm{mmHg}, 15.8 \pm 2.1 \mathrm{mmHg}$, and $16.6 \pm 2.2 \mathrm{mmHg}$ for latanoprost, travoprost, tafluprost, and bimatoprost, respectively). The difference in the baseline IOP may be a possible cause for the difference in the results. It is necessary to follow-up carefully after administration because the proportion of non-responder patients was higher after administration of omidenepag isopropyl than the prostaglandin analogs.

Further, the adverse reactions were observed in the clinical trial in the United States in 14 patients, which comprised conjunctival hyperemia, ocular hyperemia, photophobia, and eye pain, each accounting for $14.3 \%$ of patients. Adverse reactions that occurred in the clinical trial in Japan in 22 patients were conjunctival hyperemia and corneal thickening in $22.7 \%$ and $9.1 \%$ of patients, respectively. ${ }^{7}$ In another clinical trial, the primary adverse reactions, including conjunctival hyperemia, corneal thickening, eye pain, and photophobia have been reported in $24.5 \%, 11.7 \%, 4.3 \%$, and $4.3 \%$ of patients, respectively. ${ }^{8}$ In the present study, conjunctival hyperemia occurred in 3 patients $(5.6 \%)$ and eye pain occurred in 1 patient $(1.9 \%)$. The low rate of adverse reactions in this study may be because adverse reactions were evaluated at 1-2 months and 3-4 months after administration. In contrast, the adverse reactions in the clinical trials were evaluated immediately after administration (the next day) or at a comparatively short interval after administration (once a week). There was no case of discontinuation related to the study drug in the clinical trials conducted in both the United States and Japan, ${ }^{7,8}$ but $9.3 \%$ of the patients were discontinued administration in the present study. The administration was discontinued in one patient after 2 months because of insufficient IOP reduction; IOP in this patient was $20 \mathrm{mmHg}$ at baseline, $20 \mathrm{mmHg}$ after 1 month, and remained $20 \mathrm{mmHg}$ after 2 months. Loss of visual acuity by 2 or more stages was observed in 1

Table 2 Intraocular Pressure Lowering Effects of Prostaglandin Analogs for Normal-Tension Glaucoma

\begin{tabular}{|c|c|c|c|c|c|c|}
\hline Eye Drops & References & $\begin{array}{l}\text { Number of } \\
\text { Patients }\end{array}$ & $\begin{array}{l}\text { Administration } \\
\text { Period }\end{array}$ & $\begin{array}{l}\text { Pre-Treatment IOP } \\
(\mathrm{mmHg})\end{array}$ & $\begin{array}{l}\text { IOP Reduction } \\
(\mathrm{mmHg})\end{array}$ & $\begin{array}{l}\text { IOP } \\
\text { Reduction } \\
\text { (\%) }\end{array}$ \\
\hline Latanoprost & $\begin{array}{l}\text { Ishibashi et al } \\
\text { Dirks et al }\end{array}$ & $\begin{array}{l}22 \\
27\end{array}$ & $\begin{array}{l}3 \text { months } \\
3 \text { months }\end{array}$ & $\begin{array}{l}13.9 \\
16.0-16.5\end{array}$ & $\begin{array}{l}2.0 \\
2.1-2.6\end{array}$ & $\begin{array}{l}14.4 \\
12.7-16.2\end{array}$ \\
\hline Travoprost & $\begin{array}{l}\text { Mizoguchi et al } \\
\text { Mizoue et al }\end{array}$ & $\begin{array}{l}90 \\
103\end{array}$ & $\begin{array}{l}12 \text { weeks } \\
12 \text { weeks }\end{array}$ & $\begin{array}{l}15.4 \\
15.2\end{array}$ & $\begin{array}{l}2.2 \\
3.0\end{array}$ & $\begin{array}{l}14.3 \\
19.7\end{array}$ \\
\hline Tafluprost & $\begin{array}{l}\text { Mizoguchi et al }{ }^{17} \\
\text { Nakano et al }{ }^{19}\end{array}$ & $\begin{array}{l}90 \\
44\end{array}$ & $\begin{array}{l}12 \text { weeks } \\
12 \text { weeks }\end{array}$ & $\begin{array}{l}15.5 \\
13.2\end{array}$ & $\begin{array}{l}2.3 \\
3.0\end{array}$ & $\begin{array}{l}14.3 \\
22.7\end{array}$ \\
\hline Bimatoprost & $\begin{array}{l}\text { Dirks et al }{ }^{16} \\
\text { Tsumura et al. }\end{array}$ & $\begin{array}{l}33 \\
38\end{array}$ & $\begin{array}{l}3 \text { months } \\
12 \text { weeks }\end{array}$ & $\begin{array}{l}16.0-17.6 \\
14.5\end{array}$ & $\begin{array}{l}2.8-3.8 \\
3.9\end{array}$ & $\begin{array}{l}|7.5-2| .6 \\
26.9\end{array}$ \\
\hline $\begin{array}{l}\text { Omidenepag } \\
\text { Isopropyl }\end{array}$ & Present study & 54 & 3-4 months & $15.7 \pm 2.6$ & $2.0 \pm 2.0$ & $12.0 \pm 12.8$ \\
\hline
\end{tabular}

Abbreviation: IOP, intraocular pressure. 
patient. In the clinical trial, cystoid macular edema (CME) occurred with a high frequency in the pseudophakic eye as an adverse reaction after the administration of omidenepag isopropyl. ${ }^{21}$ No patient in this study had the pseudophakic eye, but the cataract eye was present. The occurrence of CME was monitored by optical coherence tomography in this study, but no occurrence was observed. Progression in cataract was the underlying cause of loss of visual acuity in the patient. However, the occurrence of CME should be appropriately monitored.

This study has a few limitations. First, the evaluation of IOP was not accurate because cases for a control group were not collected. Second, the adverse reactions, such as PAP, should be observed after the administration of the omidenepag isopropyl during a long-term follow-up, which was not done in this study. Third, the patients who had undergone the cataract surgery or had a plan to undergo the cataract surgery within 6 months were excluded from this study; therefore, the mean age of the patients was less. However, many elderly people have a history of cataract surgery; therefore, the efficacy and safety of omidenepag isopropyl should be considered for elderly people as well. Fourth, the subjects were monitored at the intervals of 1-2 months and 3-4 months after administration of omidenepag isopropyl. However, there was a difference in the interval of visits for each patient. Ideally, the interval for each patient should have been the same, but the intervals varied because this study was a retrospective analysis.

\section{Conclusion}

The present study investigated the short-term efficacy of omidenepag isopropyl in IOP lowering and safety. IOP was significantly decreased at 1-2 months and 3-4 months after administration as compared to the IOP at baseline. However, the frequency of non-responder patients was high at $22.4 \%$. Adverse reactions occurred in $7.4 \%$ of patients, who had conjunctival hyperemia or eye pain. IOP lowering effects and safety of omidenepag isopropyl for NTG patients were satisfactory in the short-term. In the future, we need to evaluate its efficacy and safety in the long-term. The long-term follow-up of patients administered with omidenepag isopropyl would enable us to consider not only the IOP lowering effects but also the inhibitory effects, including the progression of visual field defects and the presence of adverse reactions, such as PAP, that have been reported to occur after using prostaglandin analog eye drops in the long-term.

\section{Abbreviations}

CME, cystoid macular edema; IOP, intraocular pressure; NTG, normal-tension glaucoma; PAP, prostaglandin-associated periorbitopathy; POAG, primary open-angle glaucoma.

\section{Data Sharing Statement}

The participants' data that support the findings of this study are available for five years after publication from the corresponding author, Kenji Inoue, upon reasonable request.

\section{Disclosure}

K. Inoue reports grants from Santen, Alcon, Senju, Allergan, and Teijin; lecture fees from Santen, Otsuka, Senju, Kowa, Allergan, Novartis, Wakamoto, HOYA, Carl Zeiss Meditec, and Pfizer; consultant fees from Santen, Senju, and Kowa. J. Inoue reports grants from Santen, Senju, and Bayer Yakuhin; lecture fees from Santen, Senju, Pfizer, Novartis, Alcon, and Kowa. S. Kunimatsu reports lecture fees from Santen, Kowa, Novartis, Alcon, AMO, Sucampo, Pfizer, Otsuka, and Senju. K. Ishida reports lecture fees from Alcon, Pfizer, Santen, Senju, Otsuka, Kowa, AMO, Sucampo, GlaxoSmithKline, Japan Ophthalmic Instruments Association, and Nitto Medic. G. Tomita reports grants from Alcon, Eisai, Japan Focus, Pfizer, Santen, Senju, Handaya, Kowa, and Otsuka; lecture fees from Pfizer, Santen, Senju, and Otsuka, consultant fee from Allergan Japan, and non- financial support from Topcon Japan. The authors report no other conflicts of interest in this work.

\section{References}

1. Collaborative Normal-Tension Glaucoma Study Group. The effectiveness of intraocular pressure reduction in the treatment of normaltension glaucoma. Am $J$ Ophthalmol. 1998;126:498-505. doi:10.1016/S0002-9394(98)00272-4

2. The AGIS Investigators. The Advanced Glaucoma Intervention Study (AGIS): 7. The relationship between control of intraocular pressure and visual field deterioration. Am J Ophthalmol. 2000;130:429-440. doi:10.1016/S0002-9394(00)00538-9

3. Japan Glaucoma Society. Guidelines for the clinical management of glaucoma. Nippon Ganka Gakkai Zasshi. 2018;122:5-53 (in Japanese).

4. Inoue $\mathrm{K}$, Shiokawa M, Higa R, et al. Adverse periocular reactions to five types of prostaglandin analogs. Eye. 2012;26:1465-1472. doi:10.1038/eye.2012.195

5. Inoue K, Shiokawa M, Wakakura M, Tomita G. Deepening of the upper eyelid sulcus caused by 5 types of prostaglandin analogs. $J$ Glaucoma. 2013;22:626-631. doi:10.1097/IJG.0b013e31824d8d7c 
6. Inoue K, Setogawa A, Tomita G. Nonresponders to prostaglandin analogs among normal-tension glaucoma patients. J Ocul Pharmacol Ther. 2016;32:90-96. doi:10.1089/jop.2015.0086

7. Aihara M, Fenghe L, Kawata H, et al. Phase 2, randomized, dosefinding studies of omidenepag isopropyl, a selective EP2 agonist, in patients with primary open-angle glaucoma or ocular hypertension. $J$ Glaucoma. 2019;28:375-385. doi:10.1097/IJG.0000000000001221

8. Aihara M, Fenghe L, Kawata H, et al. Omidenepag isopropyl versus latanoprost in primary open-angle glaucoma and ocular hypertension: the phase 3 AYAME study. Am J Ophthalmol. 2020;S0002-9394(20) 30288-9.

9. Nakakura S, Terao E, Fujisawa Y, Tabuchi H, Kiuchi Y. Changes in prostaglandin-associated periorbital syndrome after switch from conventional prostaglandin F2 $\alpha$ treatment to omidenepag isopropyl in 11 consecutive patients. J Glaucoma. 2020;29:326-328. doi:10.1097/ IJG.0000000000001442

10. Iwase A, Suzuki Y, Araie M, et al. The prevalence of primary openangle glaucoma in Japanese: the tajimi study. Ophthalmology. 2004;111:1641-1648. doi:10.1016/j.ophtha.2004.03.029

11. Fuwa M, Toris CB, Fan S, et al. Effects of a novel selective EP2 receptor agonist, omidenepag isopropyl, on aqueous humor dynamics in laser-induced ocular hypertensive monkeys. J Ocul Pharmacol Ther. 2018;34:531-537. doi:10.1089/jop.2017.0146

12. Kirihara T, Taniguchi T, Yamamura K, et al. Pharmacologic characterization of omidenepag isopropyl, a novel selective EP2 receptor agonist, as an ocular hypotensive agent. Invest Ophthalmol Vis Sci. 2018;59:145-153. doi:10.1167/iovs.17-22745

13. Schlotzer-Schrehardt U, Zenkel M, Nüsing RM. Expression and localization of FP and EP prostanoid receptor subtypes in human ocular tissues. Invest Ophthalmol Vis Sci. 2002;43:1475-1487.

14. Inoue $\mathrm{K}$, Ishida $\mathrm{K}$, Tomita $\mathrm{G}$, Noma H. A scoping review and network meta-analysis for efficacy and safety of glaucoma medication in Japanese patients. Jpn J Ophthalmol. 2020;64:103-113. doi:10.1007/ s10384-019-00708-0
15. Ishibashi S, Hirose N, Tawara A, Kubota T. Effect of latanoprost on the diurnal variations in the intraocular and ocular perfusion pressure in normal tension glaucoma. J Glaucoma. 2006;15:354-357. doi:10.1097/01.ijg.0000212264.96864.3e

16. Dirks MS, Noecker RJ, Earl M, Roh S, Silverstein SM, Williams RD. A 3-month clinical trial comparing the IOP-lowering efficacy of bimatoprost and latanoprost in patients with normal-tension glaucoma. Adv Ther. 2006;23:385-394. doi:10.1007/BF02850159

17. Mizoguchi T, Ozaki M, Unoki K, Dake Y, Eto T, Arai M. A randomized crossover study comparing tafluprost $0.0015 \%$ with travoprost $0.004 \%$ in patients with normal-tension glaucoma. Clin Ophthalmol. 2012;6:1579-1584. doi:10.2147/OPTH.S33414

18. Mizoue S, Nakano T, Fuse N, Iwase A, Matsumoto S, Yoshikawa K. Travoprost with sofZia ${ }^{\circledR}$ preservative system lowered intraocular pressure of Japanese normal tension glaucoma with minimal side effects. Clin Ophthalmol. 2014;8:347-354. doi:10.2147/OPTH. S57640

19. Nakano T, Yoshikawa K, Kimura T, Suzumura H, Nanno M, Noro T. Efficacy and safety of tafluprost in normal-tension glaucoma with intraocular pressure of $16 \mathrm{mmHg}$ or less. Jpn J Ophthalmol. 2011;55:605-613. doi:10.1007/s10384-011-0082-7

20. Tsumura T, Yoshikawa K, Suzumura H, et al. Bimatoprost ophthalmic solution $0.03 \%$ lowered intraocular pressure of normal-tension glaucoma with minimal adverse events. Clin Ophthalmol. 2012;6:1547-1552. doi:10.2147/OPTH.S36628

21. Holló G, Aung T, Cantor LB, Aihara M. Cystoid macular edema related to cataract surgery and topical prostaglandin analogs: mechanism, diagnosis, and management. Surv Ophthalmol. 2020;65:496512. doi:10.1016/j.survophthal.2020.02.004
Clinical Ophthalmology

\section{Publish your work in this journal}

Clinical Ophthalmology is an international, peer-reviewed journal covering all subspecialties within ophthalmology. Key topics include: Optometry; Visual science; Pharmacology and drug therapy in eye diseases; Basic Sciences; Primary and Secondary eye care; Patient Safety and Quality of Care Improvements. This journal is indexed on PubMed
Dovepress

Central and CAS, and is the official journal of The Society of Clinical Ophthalmology (SCO). The manuscript management system is completely online and includes a very quick and fair peer-review system, which is all easy to use. Visit http://www.dovepress.com/ testimonials.php to read real quotes from published authors. 